\title{
Diels-Alder Cycloaddition of 2-Methylfuran and Ethylene for Renewable Toluene
}

\author{
Sara K. Green ${ }^{1,5,}$, Ryan E. Patet ${ }^{2,5,}$, Nima Nikbin ${ }^{2,5}$, C. Luke Williams ${ }^{1,5}$, \\ Chun-Chih Chang ${ }^{1,5}$, Jingye $\mathrm{Yu}^{4,5}$, Raymond J. Gorte ${ }^{4,5}$, Stavros Caratzoulas ${ }^{2,4}$, \\ Wei Fan ${ }^{1,5}$, Dionisios G. Vlachos ${ }^{2,5}$, Paul J. Dauenhauer ${ }^{3,5^{*}}$
}

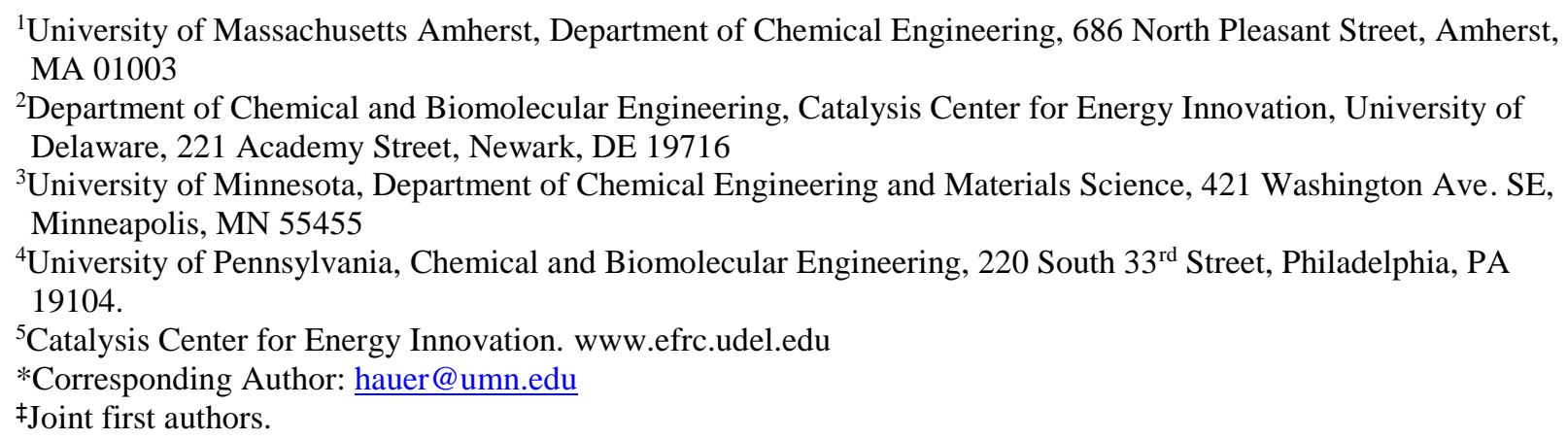

Keywords: Biomass, Toluene, Diels-Alder, Zeolite, Furan

Abstract. Diels-Alder cycloaddition of biomass-derived 2-methylfuran and ethylene provides a thermochemical pathway to renewable toluene. In this work, the kinetics and reaction pathways of toluene formation have been evaluated with H-BEA and Sn-BEA catalysts. Kinetic analysis of the main reaction chemistries reveals the existence of two rate-controlling reactions: (i) DielsAlder cycloaddition of 2-methylfuran and ethylene where the production rate is independent of the Brønsted acid site concentration, and (ii) dehydration of the Diels-Alder cycloadduct where the production rate is dependent on the Brønsted acid site concentration. Application of a reduced kinetic model supports the interplay of these two regimes with the highest concentration of toluene measured at a catalyst loading equal to the transition region between the two kinetic regimes. Selectivity to toluene never exceeded $46 \%$, as 2 -methylfuran was consumed by several newly identified reactions to side products, including dimerization of 2-methylfuran, the formation of a trimer following hydrolysis and ring-opening of 2-methylfuran, and the incomplete dehydration of the Diels-Alder cycloadduct of 2-methylfuran and ethylene. 
1.0 Introduction. Production of commodity aromatic chemicals from biomass derivatives is a promising approach for replacing current products, such as plastics, that are currently derived from petroleum. ${ }^{1,2,3,4,5,6,7}$ These chemicals include benzene, toluene, and xylenes (BTX), which are used not only in the fuel industry, but also as precursors for polymers. ${ }^{6,8}$ Specifically, benzene is used in the production of polystyrene, ${ }^{9}$ toluene is used to make polyurethane foams, ${ }^{10,11,12}$ and $p$-xylene is a precursor for terephthalic acid and polyethylene terephthalate (PET). ${ }^{1,13,14,15}$ All of these chemicals are critical to the existing infrastructure and require a sustainable method of production.

Production of BTX chemicals from biomass is part of a larger process that initially converts biomass-derived carbohydrates into furan compounds. The production of 2-methylfuran from hemicellulose is depicted in Figure 1. The main steps include: (1) hydrolysis of hemicellulose to form xylose, ${ }^{2}$ (2) dehydration of the carbohydrates to form furfural, ${ }^{1,2,3}$ and (3) hydrodeoxygenation of furfural to 2-methylfuran ${ }^{2,16,17}$ or furan. Recently, catalytic hydride transfer of $\mathrm{HMF}$ and furfural over $\mathrm{Ru} / \mathrm{C}$ using primary and secondary alcohols has also successfully produced 2,5-dimethylfuran and 2-methylfuran. ${ }^{18,19}$ Furanic compounds then undergo a symmetry-allowed [4+2] Diels-Alder cycloaddition with ethylene, followed by acidcatalyzed dehydration of the cycloadduct intermediate to the targeted aromatic compound. ${ }^{20,21}$

Diels-Alder cycloaddition of biomass-derived furanic compounds with olefins has significant potential for high yield chemical production of renewable aromatic chemicals. ${ }^{15,20,21,22}$ For the reaction of 2,5-dimethylfuran and ethylene with H-BEA zeolite catalysts, selectivity to $p$ xylene has been achieved as high as $90 \%$ at $>99 \%$ DMF conversion. ${ }^{21}$ However, Diels-Alder cycloaddition of 2-methylfuran and ethylene, shown in Figure 2, has produced only $46 \%$ selectivity to toluene at the same reaction conditions. ${ }^{21}$ Lower selectivity to aromatic compounds was presumably due to a higher occurrence of dimerization reactions as a result of 2-methylfuran having limited functionality (i.e. protecting methyl groups) at the alpha-carbon position. ${ }^{21,22,23,24,25}$

In this work, the reaction pathways and kinetics of the Diels-Alder cycloaddition of 2methylfuran and ethylene and subsequent dehydration to form toluene are more fully examined for a fundamental understanding of the active site catalytic chemistry. The existence of two kinetic regimes is revealed, corresponding to a shift in the rate-limiting step between Diels-Alder cycloaddition and dehydration chemistry. The highest concentration of toluene is produced at a 
catalyst loading corresponding to the transition region between these two regimes. Finally, the reaction network is expanded to include a 2-methylfuran trimer produced via the hydrolysis of 2methylfuran, a 2-methylfuran dimer, and incomplete dehydration isomers of the Diels-Alder cycloadduct of 2-methylfuran and ethylene. These side-products are investigated to understand the impact of incomplete and side reactions on the yield of the desired toluene product from 2methylfuran and ethylene.

2.0 Methods. Experimental results examined the short-term kinetics and long-term selectivity to toluene by the Diels-Alder reaction of 2-methylfuran and ethylene. Hybrid quantum mechanics/molecular mechanics (QM/MM) calculations were conducted to estimate the energy barriers between the reactants, products, and intermediates.

2.1 Experimental Methods. H-BEA zeolite catalyst was obtained from Zeolyst CP814E (BEA, Si/Al=12.5). The Brønsted acid site density was measured as $0.62 \mathrm{mmol} / \mathrm{gram}$ using isopropylamine TPD-TGA. ${ }^{20}$ Prior to reaction, microporous materials were calcined in a tube furnace under air flow with an online drierite tube to remove moisture present in the gas. Calcination was conducted at $550{ }^{\circ} \mathrm{C}$ for $12 \mathrm{hr}$ with a temperature ramping rate of $1{ }^{\circ} \mathrm{C} \min ^{-1}$. Sn-BEA catalysts with a Si/Sn ratio of 126 (determined by ICP-MS) were synthesized by a seeded growth method according to Chang et al. ${ }^{26}$ The sample has been demonstrated to possess mainly framework Sn by deuterated acetonitrile adsorbed FT-IR and UV-Vis spectroscopy. Since the isolated Sn site in zeolite framework contributes to Lewis acidity of the catalyst, the Lewis acid concentration in Sn-BEA was calculated based on $\mathrm{Si} / \mathrm{Sn}$ ratio to be $0.13 \mathrm{mmol} / \mathrm{g}$. Additional information on the catalyst properties and synthesis of Sn-BEA is included in the Supplementary Information.

High temperature, high pressure batch reactions for the production of toluene from 2methylfuran and ethylene were conducted using a $160 \mathrm{ml}$ Parr Reactor. The $100 \mathrm{ml}$ reaction solution consisted of n-heptane solvent (Alfa Aesar, 99\%), 2-methylfuran reactant (Alfa Aesar, 98\%), and n-tridecane (Alfa Aesar, 98\%) as an internal standard. For a given reaction, the reaction vessel was loaded with the liquid reactant solution and 0 to 0.77 grams of the solid zeolite catalyst before being sealed. The reactor was purged with $\mathrm{N}_{2}$ to remove air. The system temperature was then increased to between 200 and $275^{\circ} \mathrm{C}$ and, once the desired temperature was achieved, 200 psi partial pressure of ethylene was introduced to the reactor vessel. A liquid 
sample was collected at this time, which represented the initial reaction time (zero minutes) in experimental results.

Calculation of selectivity to liquid products compared the moles of 2-methylfuran consumed for a product to the sum of the equivalent moles of 2-methylfuran for all liquid products. Carbon balances were calculated by comparing the equivalent moles of 2-methylfuran in a product sample to the equivalent moles of 2-methylfuran at time zero. Equivalent moles were assumed as follows: one mole for the incomplete dehydration isomers and alkylated products, two moles for the 2-methylfuran dimer and unidentified polymers, and three moles for the 2-methylfuran trimer. Gas products were not analyzed for these reactions, and thus reactant and product species in the vapor phase were not considered in the carbon balance. The concentration of acid sites was calculated using the mass of catalyst loaded into the reactor, the concentration of acid sites $(\mathrm{g} / \mathrm{mol})$ of the catalyst, and the initial liquid volume of the reactant solution. Liquid samples were analyzed using an Agilent 7890A gas chromatograph with a Restek Stabiliwax®-DA column. GC-MS analysis was conducted using an Agilent 7890A connected to a 5975C inert XL MSD with Triple-Axis Detector.

2.2 Computational Methods. Gas-phase quantum chemical calculations for the Diels-Alder reaction and the dehydration of its product (cycloadduct) to toluene in the absence of catalyst were carried out at the M06-2X/6-311G(2df,p) theory level. ${ }^{27}$ Mechanistic studies of the two reactions in the Brønsted acidic zeolite H-BEA were carried out by hybrid QM/MM (quantum mechanics/molecular mechanics) calculations with a mechanically embedded cluster model. The H-BEA model was constructed by extracting the active site and the surrounding zeolite framework atoms from the periodic structure of H-BEA and constructing a three-layer ONIOM model (Figure 4A). ${ }^{28,29} \mathrm{~A}$ single framework silicon atom was replaced with an aluminum atom and a proton was incorporated to balance the charge. The high layer of the ONIOM model contains 16 tetrahedral atoms surrounding the substituted aluminum atom and all reacting molecules; this layer was treated at the M06-2X/6-311G(2df,p) theory level. The intermediate ONIOM layer contains 18 tetrahedral atoms around the high layer and was treated at the M062X/3-21G theory level. The remaining 77 tetrahedral atoms of the cluster make up the low ONIOM layer and were treated using the universal force field (UFF). ${ }^{27,30}$ All dangling bonds were saturated with hydrogen atoms, for a model with a stoichiometry of $\mathrm{AlH}_{105} \mathrm{O}_{170} \mathrm{Si}_{110}$. For all calculations, the high layer was allowed to relax, while the intermediate and low layer atoms 
were frozen in their crystallographic positions. Potential energy minima and transition states were confirmed by frequency and IRC (Intrinsic Reaction Coordinate) calculations. The Gaussian 09 program was used for all the calculations. ${ }^{31}$

3.0 Results. Experiments were conducted which revealed conditions where the toluene production rate is both dependent and independent of the Brønsted acid site concentration. Activation energies and product distributions were experimentally measured at various conditions to further investigate system Brønsted acid site concentration for comparison with QM/MM computations.

3.1 Rate of Toluene Production. Investigation of the initial kinetics for the production of toluene from 2-methylfuran and ethylene at low conversion $\left(\mathrm{X}_{\mathrm{MF}}<15 \%\right)$ reveals two distinct kinetic regimes with respect to concentration of Brønsted acid sites (Figure 3a). The transition is apparent for $\mathrm{H}-\mathrm{BEA}(\mathrm{Si} / \mathrm{Al}=12.5,0.62$ moles Brønsted acid sites per gram catalyst $)$ at both 200 ${ }^{\circ} \mathrm{C}$ and $250{ }^{\circ} \mathrm{C}$. In both reaction systems, at less than 0.7 mmoles of Brønsted acid site per liter of reaction solution, there exists a linear relationship between the rate of toluene production and the concentration of Brønsted acid sites. At $250{ }^{\circ} \mathrm{C}$, the reaction rate is independent of Brønsted acid sites at greater than $2.0 \mathrm{mM}$, while at $200{ }^{\circ} \mathrm{C}$, the reaction rate is independent of Brønsted acid sites at greater than $0.7 \mathrm{mM}$.

3.2 Main Reaction - Activation Energies. Activation energies were experimentally measured at conditions where a dependence with Brønsted acid site concentration ( $0.11 \mathrm{mM})$ was observed, and at conditions where no dependence on Brønsted acid site concentration (3.5 $\mathrm{mM}$ ) was observed, as identified in Figure 3b, using H-BEA (Si/Al 12.5) catalyst. The low catalyst loading kinetic regime (dehydration-limited) exhibits a kinetic energy barrier of $9.72 \pm$ $1.02 \mathrm{kcal} / \mathrm{mol}$, while the high catalyst loading kinetic regime (cycloaddition-limited) exhibits a kinetic energy barrier of $20.4 \pm 0.64 \mathrm{kcal} / \mathrm{mol}$, as depicted in the Arrhenius plots of Figure $3 \mathrm{~b}$.

Reaction barriers for the mechanisms of the main reaction (Table 1) have been calculated in the gas phase and within the structure of H-BEA zeolite catalyst (Figure 4a). The Diels-Alder reaction enthalpy was calculated to be $26.0 \mathrm{kcal} / \mathrm{mol}$ in the gas phase and $23.4 \mathrm{kcal} / \mathrm{mol}$ in the zeolite, indicating that the Brønsted acidity has no significant catalytic effect on the Diels-Alder reaction. The Diels-Alder product, an oxanorbornene derivative, then undergoes dehydration to form toluene and water, as shown in Figure 2. Dehydration starts with the breaking of the C-O- 
$\mathrm{C}$ bridge. In H-BEA, this step requires $17.7 \mathrm{kcal} / \mathrm{mol}$ of activation energy, a significant reduction from the gas-phase value of $62.6 \mathrm{kcal} / \mathrm{mol}$. Another distinction was observed when investigating the bridge $\mathrm{C}-\mathrm{O}$ cleavage in oxanorbornene; when the $\mathrm{C}-\mathrm{O}-\mathrm{C}$ bridge is cleaved on the non-methyl side of oxanorbornene (Figure $4 \mathrm{~b}$ ), then the barrier was calculated to be $32.4 \mathrm{kcal} / \mathrm{mol}$, while if it occurs on the methyl side of oxanorbornene (Figure 4c), the barrier was significantly lower at only $17.7 \mathrm{kcal} / \mathrm{mol}$.

3.3 Identification of Side-Products. An expanded reaction scheme is shown in Figure 2, which includes: (i) the reaction of 2-methylfuran [1] and ethylene to form the MF/ethylene cycloadduct [2], which (ii) dehydrates to form toluene [3]; (iii) the ring-opening of 2methylfuran to 4-oxopentanal [4], which (iv) alkylates with additional 2-methylfuran molecules to form the 2-methylfuran trimer [5]; (v) the dimerization of 2-methylfuran to form the 2methylfuran dimer [6]; and (vi) the formation of polymerized [7] and alkylated products [8]. Incomplete dehydration isomers are not included in this reaction scheme.

A typical gas chromatogram of the product mixture and compound retention times is provided in the Supplementary Information. Peaks containing the majority of the analyte area were identified as n-heptane solvent, 2-methylfuran reactant, tridecane internal standard, and product toluene. Selectivity towards alkylated products, such as benzene, ortho- and paraethyltoluene, and ortho-, meta-, and para-xylene, was less than 5\%, and their identities were confirmed by comparison with known standards.

Two incomplete dehydration isomers (ID isomers \#1 and \#2) were identified by GC-MS as six-member rings containing a methyl group and a ketone (see Supplementary Information). It was assumed that this structure actually contains an epoxide, rather than a ketone, based on computational results of the most stable structure of a similar intermediate in the 2,5dimethylfuran/ethylene system. ${ }^{32}$ A species was identified by GC-MS as the dimer formed from the cycloaddition of two 2-methylfuran molecules. Similarly, a 2-methylfuran trimer, 5,5bisylvyl-2-pentanone, is formed by the hydrolysis of 2-methylfuran to form 4-oxopentanal followed by alkylation with two additional 2-methylfuran molecules..$^{23,25,33,34}$ For this work, 5,5bisylvyl-2-pentanone was synthesized using a mixture of 2-methylfuran and water with sulfuric acid as a catalyst. The identity of the 2-methylfuran trimer was confirmed by GC-MS, which matched the parent ion and fragmentation pattern (See Supplementary Information). Comparison of the gas chromatogram elution time containing the trimer with the chromatogram derived from 
the 2-methylfuran/ethylene product mixture identified the 2-methylfuran trimer as a sideproduct.

3.4 Rate of Side Product Production. Figure 5 shows the rate of production of the 2methylfuran trimer, 2-methylfuran dimer, ID isomers, and toluene as a function of Brønsted acid site concentration. At $250{ }^{\circ} \mathrm{C}$ (Figure 5a), the rates of production of the ID isomers were comparable to that of toluene and also exhibit two kinetic regimes. The rate of ID isomer \#2 followed the same trend as the rate of toluene when fewer than $2.0 \mathrm{mM}$ Brønsted acid sites are present, and then decreased with increasing acid site concentration above $2.0 \mathrm{mM}$. The rate of production of ID isomer \#1 was higher than all other products at low acid site concentration ( $<1.5 \mathrm{mM}$ Brønsted acid sites), and was observed to decrease at concentrations $>0.5 \mathrm{mM}$. The rates of production of the 2-methylfuran trimer and the 2-methylfuran dimer increase with increasing Brønsted acid site concentration as shown in Figure 5a, which indicated that both are catalyzed by Brønsted acidity. The 2-methylfuran trimer rate appeared to level off at concentrations of Brønsted acid sites $>1.5 \mathrm{mM}$. The rate of production of the 2-methylfuran dimer did not exhibit a plateau for the range of catalyst loadings tested.

When the reaction temperature was decreased to $200{ }^{\circ} \mathrm{C}$, as seen in Figure $5 \mathrm{~b}$, the rates of production of toluene and the identified side products decreased, as expected. At these conditions, the product reaction rate indicated that dehydration was the rate-limiting reaction for toluene production at less than $0.7 \mathrm{mM}$ Brønsted acid sites while cycloaddition was the ratelimiting reaction for toluene production for greater than $0.7 \mathrm{mM}$ Brønsted acid sites. Similar to Figure 5a, the rate of production of ID isomers was comparable to toluene production, but with production of ID isomer \#1 slightly higher at low catalyst loading. The rate of production of 2methylfuran dimer was again lower than the other side-products. At $250{ }^{\circ} \mathrm{C}$ the trimer formation rate was significantly lower than toluene; however, at $200{ }^{\circ} \mathrm{C}$ the rate of trimer production surpassed the rate of toluene at high catalyst loading. Additionally, selectivity towards the trimer at $200^{\circ} \mathrm{C}$ was $\sim 52 \pm 5 \%$ at $<3 \mathrm{hrs}$ of reaction time. This indicates that the reaction could be tuned to selectively make the 2-methylfuran trimer over toluene at lower temperatures and higher catalyst loadings.

3.5 Reaction Rate Orders. Reaction rate orders with respect to ethylene, 2-methylfuran, and Brønsted acid sites were determined at both low and high catalyst loadings for toluene and the main side-products as reported in Table 2. Experiments evaluated reaction orders at low 
conversion by varying the concentration of 2-methylfuran, ethylene, or Brønsted acid sites while holding the concentration of the other two components constant. In the dehydration-limited kinetic regime (i.e. low acid catalyst loading), the ID isomer \#2, 2-methylfuran trimer, and 2methylfuran dimer all exhibited reactions orders of approximately one with respect to acid sites while this reaction order was fractional for toluene and the ID isomer \#1.

In the cycloaddition-limited kinetic regime (i.e. high acid catalyst loading), the reaction rate order with respect to acid sites for the 2-methylfuran dimer remained first order $(0.96 \pm$ 0.04); however, the reaction rate orders for all other products were lower than in the dehydrationlimited regime. Both toluene and the 2-methylfuran trimer exhibited reaction rate orders of approximately zero, while the ID isomers exhibited negative reaction orders with respect to acid site concentration.

Toluene and the ID isomers were formed along the same reaction pathway and thus it was expected that they have similar reaction rate orders with respect to 2-methylfuran and ethylene. As shown in Table 2, this was the case in the cycloaddition-limited kinetic regime (i.e. high acid catalyst loading), where the reaction orders with respect to 2-methylfuran and ethylene were approximately one for all three products. However, in the dehydration-limited regime (i.e. low acid catalyst loading), the reaction rate orders with respect to 2-methylfuran for the formation of these three products were mainly fractional $(0.53 \pm 0.04,0.76 \pm 0.03$, and $0.41 \pm 0.05$ for toluene, ID isomer \#1, and ID isomer \#2, respectively). The reaction rate order with respect to ethylene was approximately one for both ID isomers, but was $0.68 \pm 0.02$ for formation of toluene.

Measured reaction rate orders for the formation of the 2-methylfuran trimer and dimer were unexpected, and it is possible that the kinetic parameters for these products were difficult to isolate due to low concentrations and reaction rates. The reaction rate order with respect to ethylene for both of these products in both regimes was expected to be zero, as neither product included ethylene reactant. However, the reaction order of ethylene for formation of the dimer in the dehydration-limited regime was $0.41 \pm 0.04$. The reaction rate orders with respect to 2methylfuran for the 2-methylfuran dimer were $0.64 \pm 0.10$ and $0.09 \pm 0.04$ in the dehydrationand cycloaddition-limited regimes, respectively. The reaction rate orders with respect to 2methylfuran for the 2-methylfuran trimer were $1.34 \pm 0.13$ and $2.26 \pm 0.30$ in the dehydrationand cycloaddition-limited regimes, respectively. Higher concentrations of these products are 
required for more accurate reaction orders to be calculated.

3.6 Long Term Results. Figure 6a shows the concentration profiles of toluene and the mainside products at $250{ }^{\circ} \mathrm{C}$ with $2.1 \mathrm{mM}$ acid sites $\mathrm{H}$-BEA ( $\mathrm{Si} / \mathrm{Al} 12.5,0.3$ grams) as a function of time for the first 30 hours of reaction. 2-methylfuran conversion was $\sim 91 \%$ after seven hours of reaction time and $\sim 100 \%$ after 24 hours. The concentration of both toluene and unidentified polymers increased for the first 10 hours of reaction before leveling off. The concentrations of the ID isomers reached a maximum around $3.5 \mathrm{hrs}$, and the concentration profile suggests that the isomers were intermediates for other products, potentially including solid residue on the catalyst surface, at long reaction time. TGA analysis of the spent catalyst particles reveals that $39 \pm 2.5 \%$ of the H-BEA weight after 48 hours of reaction was 'coke'. If the coke is comprised of 2-methylfuran, as opposed to ethylene polymers, this amount corresponds to $4.3 \pm 1 \%$ of the initial 2-methylfuran concentration. The carbon balance was $79 \pm 4 \%$ for the first 12 hours of reaction and $72 \pm 5 \%$ by 48 hours. The decrease in carbon balance could be a result of the ID isomers polymerizing to larger polymers or to solid residue. Concentrations of the 2methylfuran dimer and alkylated products increased for the 30 hours of reaction time but did not exceed $0.02 \mathrm{M}$. The 2-methylfuran trimer was observed at $<7 \mathrm{hr}$ reaction time, and its concentration decreased throughout the reaction. A comparison of trimer concentrations from before and after heating the reactor revealed that $77 \%$ of the maximum concentration of the trimer was formed during the heating process. This is significantly higher than other products such as toluene or the unidentified polymers, where only $4 \%$ and $9 \%$, respectively, of the maximum concentration was formed during heating. When the reaction is conducted at $275^{\circ} \mathrm{C}$ and using 0.77 grams of H-BEA, the heating period accounts for less than $1 \%$ of the maximum toluene concentration but $~ 96 \%$ of the maximum trimer concentration and 33\% of the maximum unidentified polymer concentration.

Figure $6 \mathrm{~b}$ depicts the concentration profile of toluene as a function of reaction time for two catalyst loadings and temperatures, and it shows that the highest concentration of toluene was achieved at a catalyst loading near the transition point between the two kinetic regimes. For a given catalyst loading, conducting the reaction at higher temperatures produces higher rates of formation of toluene but does not produce a higher final toluene concentration. At a given temperature, conducting the reaction with lower amounts of catalyst (within the cycloadditionlimited regime) produced higher concentrations of toluene. As shown in Figure $7 \mathrm{a}$ and $7 \mathrm{~b}$, 
increased catalyst loading within the cycloaddition-limited kinetic regime also decreased the maximum concentration of both ID isomers, which could result from high catalyst loading increasing the formation of larger polymers.

Figure $7 \mathrm{c}$ shows that high temperatures and high catalyst loadings are favorable for formation of the 2-methylfuran dimer. However, the concentration of the 2-methylfuran trimer, shown in Figure $7 d$, decreased drastically with increasing temperature and does not exhibit a strong dependence on catalyst loading. The highest concentration of the 2-methylfuran trimer was achieved at $200{ }^{\circ} \mathrm{C}$ at catalyst concentrations exceeding $5.4 \mathrm{mM}$, as expected from the 200 ${ }^{\circ} \mathrm{C}$ kinetic regime plot shown in Figure 7b. Selectivity towards the trimer at these conditions was $52 \pm 5 \%$ at $<3$ hrs of reaction time. Hydrodeoxygenation of the 2-methylfuran trimer, and similar 2-methylfuran derived molecules, has been shown to be an important reaction in the production of renewable diesel fuel. ${ }^{23,24,33,34,35}$

3.7 Effect of Lewis Acidity. The reaction of 2-methylfuran and ethylene was also conducted with Lewis acid sites within Sn-BEA (1 mM Lewis acid sites) and a physical mixture of 10:1 Lewis acid sites (Sn-BEA, $1.0 \mathrm{mM}$ acid sites) to Brønsted acid sites (H-BEA (0.11 mM acid sites). It has previously been shown that, for the Diels-Alder cycloaddition of 2,5-dimethylfuran and ethylene, Lewis acidity will catalyze the dehydration reaction to a lesser extent than Brønsted acidity. ${ }^{32}$ Previous studies on cation-exchanged Lewis acid zeolites have shown that the Diels-Alder cycloaddition reaction is not significantly catalyzed in these systems, ${ }^{32,36,37}$ but there is less of an understanding of how framework-substituted Lewis acid zeolites, such as Sn-BEA, affect the chemistry. ${ }^{39}$

As shown in Figure 8, the reaction with Sn-BEA catalyst produced higher concentrations of the ID isomers than H-BEA catalyst. The rate of production of ID isomer \#1 was also higher at $6.26 \pm 0.35 \mathrm{mmoles} / \mathrm{hr}$ and $6.04 \pm 0.45 \mathrm{mmoles} / \mathrm{hr}$ with Sn-BEA and 10:1 Sn-BEA:H-BEA, respectively, compared to $2.91 \pm 0.23 \mathrm{mmoles} / \mathrm{hr}$ over H-BEA. Concentrations of toluene and the 2-methylfuran dimer were lower with Sn-BEA, while no change was observed for the concentration of the 2-methylfuran trimer. The production rate of ID isomer \#2 was lower with Sn-BEA (1.06 $\pm 0.07 \mathrm{mmoles} / \mathrm{hr})$ and 10:1 Sn-BEA:H-BEA $(1.87 \pm 0.25 \mathrm{mmoles} / \mathrm{hr})$ as compared to H-BEA $(2.39 \pm 0.22 \mathrm{mmoles} / \mathrm{hr})$. The same trend was observed for production of toluene with rates of $1.56 \pm 0.31 \mathrm{mmoles} / \mathrm{hr}$ with $\mathrm{Sn}-\mathrm{BEA}, 1.69 \pm 0.20 \mathrm{mmoles} / \mathrm{hrand}$ with 10:1 Sn-BEA:H-BEA, and $2.40 \pm 0.36$ mmoles/hr with H-BEA. 
4.0 Discussion. Experimental results were used to assess both the main and side reaction for the toluene production rate and selectivity to products. A reduced model was parameterized and fit, which demonstrated the similarities in the main pathway of the formation of toluene from methylfuran and ethylene to the production of $p$-xylene from 2,5-dimethylfuran and ethylene. The side products from the reaction of 2-methylfuran and ethylene were studied to understand the origin of lower selectivity to toluene compared to the high selectivity to $p$-xylene observed previously.

4.1 Main Reaction. Prior work has shown that the formation of aromatic chemicals from furanics and ethylene is controlled by a two-step reaction mechanism; the (1) Diels-Alder cycloaddition of 2-methylfuran and ethylene to form an oxanorbornene intermediate, and (2) subsequent dehydration to form the desired toluene and water (Figure 2). ${ }^{20,21,37}$ This two-step reaction mechanism results in interesting kinetic behavior in the rate of toluene production, as shown in Figure 3a. At less than $0.7 \mathrm{mM}$ of Brønsted acid sites, there exists a linear relationship between rate of toluene production and the concentration of Brønsted acid sites. Active site dependence indicates that the rate-limiting reaction for this regime is dehydration, which is Brønsted acid catalyzed. At greater than $2.0 \mathrm{mM}$ of Brønsted acid sites, the reaction rate is independent of Brønsted acid site concentration, which indicates that the rate-limiting reaction for this kinetic regime is likely non-Brønsted acid catalyzed Diels-Alder cycloaddition.

This proposed two-step mechanism has been shown to exhibit the two regime behavior seen experimentally in Figure 3a through use of a reduced kinetic model originally developed for the production of $p$-xylene from 2,5-dimethylfuran and ethylene in H-Y zeolite. ${ }^{37}$ This model can be re-derived for the rate of toluene production from 2-methylfuran and ethylene and reparameterized using values obtained from the QM/MM calculations (Table 3) as,

$$
\boldsymbol{r}_{\boldsymbol{T}}=\frac{\left(\frac{k_{2} K_{1} K_{4}}{1+K_{3} C_{W}}\right) C_{M F} C_{E} C_{* t}}{K_{6} C_{M F}+\left(\frac{k_{2}}{k_{-1}}\right)\left(\frac{K_{4}}{1+K_{3} C_{W}}\right) C_{* t}}
$$

where $\mathrm{k}_{\mathrm{i}}$ are the kinetic parameters for the $\mathrm{i}^{\text {th }}$ reaction, $\mathrm{K}_{\mathrm{i}}$ are the equilibrium constants for the $\mathrm{i}^{\text {th }}$ reaction, $\mathrm{C}_{\mathrm{i}}$ is the concentration of the $\mathrm{i}^{\text {th }}$ component, and $\mathrm{C}_{*} \mathrm{t}$ is the total Brønsted acid site concentration in the system. Comparison of the rate of toluene production predicted by the reduced model (Figure 3a) reveals that the main chemistry describes the toluene production rate well. This reduced model reveals the presence of a dehydration limited regime dependent on the 
acid site concentration at low catalyst loadings and of a Diels-Alder limited regime independent of the acid site concentration at high catalyst loadings.

Experimentally-measured activation energies of $9.72 \mathrm{kcal} / \mathrm{mol}$ in the low catalyst loading kinetic regime (dehydration-limited) and $20.4 \mathrm{kcal} / \mathrm{mol}$ in the high catalyst loading kinetic regime (Diels-Alder cycloaddition-limited) are comparable to the computed acid-catalyzed dehydration reaction barrier of $17.7 \mathrm{kcal} / \mathrm{mol}$ and homogeneous Diels-Alder reaction barrier of $23.4 \mathrm{kcal} / \mathrm{mol}$. Qualitatively, the shift in rate limiting step from the linear regime to the plateau regime are supported by the change in experimentally-determined and computed reaction barriers for the individual reaction steps.

Additionally, the difference in the $\mathrm{C}-\mathrm{O}$ cleavage reaction barrier on the methyl and nonmethyl sides of the oxanorbornene intermediate (depicted in Figure 4d) fit within expected results. The cleavage of the $\mathrm{C}-\mathrm{O}$ bond on the methyl side of the molecule has a barrier (17.7 $\mathrm{kcal} / \mathrm{mol})$ that is lower than the Diels-Alder cycloaddition reaction barrier $(26.8 \mathrm{kcal} / \mathrm{mol})$, so that two distinct kinetic regimes exist, depending on the Brønsted acid catalyst loading. On the non-methyl side of the molecule, the dehydration barrier remains higher $(32.4 \mathrm{kcal} / \mathrm{mol})$ than the Diels-Alder cycloaddition reaction barrier, such that no plateau kinetic regime would be expected, and an increase in the Brønsted acid active site concentration would always affect the rate-limiting step of the reaction. The difference between two $\mathrm{C}-\mathrm{O}$ cleavage barriers is comparable to the dehydration of a tertiary alcohol on the methyl side of the molecule and of a secondary alcohol on the non-methyl side of the molecule, which supports the lower reaction barrier on the methyl side of the molecule (green in Figure 4d). ${ }^{40}$

4.2 Side Reactions. The absence of a protecting methyl group on the alpha carbon of the furan ring in methylfuran increases the number of possible side reactions, as compared to the DielsAlder cycloaddition of 2,5-dimethylfuran and ethylene..$^{21,22,23,24,25}$ The main side products have been identified as a 2-methylfuran dimer, a 2-methylfuran trimer, and two isomers of incomplete dehydration of the cycloadduct. The 2-methylfuran dimer is formed from the cycloaddition of two 2-methylfuran molecules. The rate of its formation is an order of magnitude lower than other products, as shown in Figure 6, and its formation rate depends on the concentration of Brønsted acid sites, which indicates that the reaction is always kinetically limited by dehydration. The reaction order of one with respect to acid sites (Table 2) indicates that only one of the 2-methylfuran molecules may be adsorbed on the catalyst active site for this reaction. 
Fractional orders with respect to 2-methylfuran and ethylene are unexpected as the reaction requires two 2-methylfuran molecules and no ethylene molecules. It is therefore possible that the concentration and rate of formation of this product are sufficiently low that the reaction order cannot be decoupled from the other products.

Hydrolysis of furan molecules is known to be Brønsted acid catalyzed to form a ringopened structure. ${ }^{41}$ Hydrolysis of 2-methylfuran forms 4-oxopentanal, which can undergo alkylation with two additional 2-methylfuran molecules to form the 2-methylfuran trimer. $^{23,25,33,34}$ 4-oxopentanal can also reversibly react to form 2-methylfuran and water, similar to the equilibrium between 2,5-dimethylfuran and 2,5-hexanedione. ${ }^{20,21}$ Figure 6a showed that the rate of formation of the trimer exhibits two kinetic regimes with respect to acid site concentration. At low catalyst loading, the rate of trimer formation increases linearly and the reaction order with respect to acid sites is one. This is consistent with 2-methylfuran trimerization being acid catalyzed. ${ }^{25}$ At high catalyst loading, the reaction order for trimer formation with respect to acid sites, reported in Table 2, is approximately zero. This may be due to a lack of water production (derived from cycloadduct dehydration), which is required for methylfuran hydrolysis, as the rate of toluene production does not increase in the cycloadditionlimited regime.

A potential reaction scheme for the production of the ID isomers is depicted in Figure 4d. Based on the energy barriers presented in Table 3, it is likely that the Diels-Alder cycloadduct initially undergoes $\mathrm{C}-\mathrm{O}$ bond cleavage at the methyl group. ID isomer \#1 is formed when the oxygen remains attached as an epoxide, instead of leaving as water. ${ }^{32}$ ID isomer \#1 could then undergo a proton transfer to form an alcohol, which is potentially ID isomer \#2. This structure has the same molecular weight as the epoxide, but has undergone an additional acid-catalyzed step towards complete dehydration. This could explain why ID isomer \#1 exhibits a high reaction rate at low catalyst loading, while ID isomer \#2 has rates similar to toluene.

The Sn-BEA system led to an increased rate of production and concentration of ID isomer \#1, but not ID isomer \#2 or toluene as compared to H-BEA. High concentrations and rates of formation of the ID isomers indicate that the cycloadduct intermediate is either formed in solution or desorbs from acid sites prior to completing dehydration, thereby forming ID isomers instead of toluene. A full understanding of how the Sn-BEA active sites behave with this chemistry is unknown. The Lewis acid catalyst could produce a higher amount of the 
cycloadduct intermediate if the Sn-BEA active site catalyzes the cycloaddition reaction. Lowering of the Diels-Alder reaction barrier would result in higher concentrations of oxanorborne, which would favor the formation of ID isomer \#1, rather than ID isomer \#2. Alternatively, studies of Sn-BEA for the isomerization of glucose have shown that Sn-BEA active sites can be hydrolyzed to form open Brønsted acid sites. ${ }^{42}$ In this reaction system, hydrolysis of the active sites could occur with the water formed from dehydration of the cycloadduct. In this case, the open Brønsted acid site of Sn-BEA could behave similarly to the Brønsted acid site of H-BEA to catalyze the dehydration reaction barrier; however, further studies are needed to identify the mechanisms associated with Sn-BEA and assess the differences between the Sn-BEA and H-BEA catalysts.

Figure 9 depicts the ratio of the rate of formation of the main side products to the rate of formation of toluene with H-BEA catalyst in the dehydration-limited kinetic regime $(0.37 \mathrm{mM}$ acid sites), the transition region (2.12 $\mathrm{mM}$ acid sites), and the cycloaddition-limited regime (5.41 $\mathrm{mM}$ acid sites). Figure 9a shows that the ratio of the rate of formation of the ID isomers to the rate of formation of toluene decreases with increasing catalyst loading. This result is expected, as the rates of ID isomer formation are highest when the system is limited by dehydration and lowest when the system is limited by the cycloaddition reaction. Therefore, a high catalyst loading may produce the greatest amount of toluene, due to the low ratio of ID isomer formation rate (i.e. the main side products) to toluene formation rate. However, the experimental results presented in Figure $6 \mathrm{~b}$ showed that the highest concentration of toluene was actually produced using a catalyst loading near the transition region between kinetic regimes. This is likely because the highest catalyst loading not only promotes toluene formation, but also promotes formation of larger polymers. This is supported by Figure 7c, where the concentration of the 2-methylfuran dimer is observed to increase with increased catalyst loading. Although the ratio of the rate of formation of the trimer and dimer increase with increasing catalyst loading (Figure 9b), these side products are present in significantly lower concentrations than toluene and do not consume a significant portion of the 2-methylfuran. Therefore, it is likely that other polymeric species, resulting from reactions between the cycloadduct and 2-methylfuran or toluene, are the cause of the lower toluene concentrations at high catalyst loading.

Previously, a selectivity of $46 \pm 2 \%$ to toluene was measured at $250{ }^{\circ} \mathrm{C}$ and 0.5 grams of H-BEA. ${ }^{21}$ This work achieved the same selectivity to toluene by examining $99 \%$ conversion of 
2-methylfuran over $0.3-0.77$ grams H-BEA and $250-275^{\circ} \mathrm{C}$. Higher catalyst loading shifted the product distribution away from ID isomers and towards larger polymers, which were unidentified. Higher reaction temperatures increased the reaction rate for all components, except the 2-methylfuran trimer, and did not affect the distribution of products. Experiments using H-Y, H-ZSM-5, and H-Mordenite resulted in toluene selectivities <35\% (See Supplemental Information). It has been shown that the ID isomers consume a large quantity of the 2methylfuran; the combined selectivity to 6-carbon products (toluene and the two ID isomers) was $61.7 \pm 0.2 \%$. Therefore, the reactions that form the ID isomers must either be pushed towards complete dehydration or avoided if selectivity to toluene is to be increased in future work.

5.0 Conclusion. The reaction network for the reaction of 2-methylfuran and ethylene with H-BEA catalyst has been expanded to include products such as incomplete dehydration isomers, a 2-methylfuran dimer, and a 2-methylfuran timer that are not detected or present in low quantities in the similar reaction of 2,5-dimethylfuran and ethylene. The prevalence of these side reactions is due to the unprotected alpha carbon on the furan ring for 2-methylfuran. The existence of two distinct reaction kinetic regimes with respect to the concentration of Brønsted acid site was discovered, with each kinetic regime corresponding to a different rate-limiting reaction (oxonorborene dehydration or Diels-Alder cycloaddition). These kinetic regimes also exist for the incomplete dehydration isomers of oxonorborene, and the ratio of the rates of formation of the products supports the proposed chemical structures of these byproducts. The highest concentration of toluene was measured at a catalyst loading equal to the transition region between the two kinetic regimes; however, selectivity to toluene never exceeded $46 \%$. Further improvements in catalyst design require capability for complete dehydration of Diels-Alder cycloadducts to six-carbon aromatic rings. These results provide a deeper understanding of the more general Diels-Alder cycloaddition of furan-based feedstocks and olefins and will facilitate optimization of the production of additional important biomass-derived aromatic chemicals.

\section{ACKNOWLEDGEMENTS}

Financial support was provided from the Catalysis Center for Energy Innovation, a U.S. Department of Energy - Energy Frontiers Research Center (www.efrc.udel.edu) under Award DE-SC0001004. This research used resources of the National Energy Research Scientific 
Computing Center (NERSC), a DOE Office of Science User Facility supported by the Office of Science of the U.S. Department of Energy under Contract No. DE-AC02-05CH11231. 
Table 1. Computed Activation Energies for the Diels-Alder and Subsequent Dehydration Reaction of 2Methylfuran and Ethylene. Diels-Alder and Cycloadduct $\mathrm{C}-\mathrm{O}$ bond scission activation enthalpies from quantum chemical calculations in the gas phase and in H-BEA zeolite modeled by a mechanically embedded three-layer ONIOM cluster model.

\begin{tabular}{|c|c|c|c|c|c|c|}
\hline \multirow[b]{3}{*}{ System } & \multicolumn{3}{|c|}{$\Delta \mathrm{E}_{\mathrm{rxn}, 0 \mathrm{~K}}(\mathrm{kcal} / \mathrm{mol})$} & \multicolumn{3}{|c|}{$\Delta H_{\text {rxn,523K }}(\mathrm{kcal} / \mathrm{mol})$} \\
\hline & \multirow[t]{2}{*}{ Diels-Alder } & \multicolumn{2}{|c|}{$\begin{array}{l}\text { Dehydration } \\
\text { (C-O Cleavage) }\end{array}$} & \multirow[t]{2}{*}{ Diels-Alder } & \multicolumn{2}{|c|}{$\begin{array}{l}\text { Dehydration } \\
\text { (C-O Cleavage) }\end{array}$} \\
\hline & & $\begin{array}{l}\text { Methyl } \\
\text { Side }\end{array}$ & $\begin{array}{c}\text { Non-Methyl } \\
\text { Side }\end{array}$ & & $\begin{array}{c}\text { Methyl } \\
\text { Side }\end{array}$ & $\begin{array}{c}\text { Non-Methyl } \\
\text { Side }\end{array}$ \\
\hline Gas Phase & 26.8 & 60.9 & 64.2 & 26.0 & 62.6 & 65.9 \\
\hline H-BEA & 25.5 & 17.3 & 32.2 & 23.4 & 17.7 & 32.4 \\
\hline
\end{tabular}


Table 2. Kinetic Rate Expression Orders for the Reaction of 2-Methylfuran (MF) and Ethylene. Reaction orders were determined for $\mathrm{MF}$, ethylene, and acid sites at low $(0.112 \mathrm{mM}[\mathrm{H}+])$ and high $(3.5 \mathrm{mM}[\mathrm{H}+])$ loadings of $\mathrm{H}-\mathrm{BEA}(\mathrm{Si} / \mathrm{Al} 12.5)$ at $250^{\circ} \mathrm{C}$ for the formation of toluene, ID isomers, and $\mathrm{MF}$ dimers/trimers.

\begin{tabular}{ccccccc}
\hline \multirow{2}{*}{ Product } & \multicolumn{2}{c}{ Dehydration-Limited Regime } & \multicolumn{3}{c}{ Cycloaddition-Limited Regime } \\
& MF & Ethylene & Acid Sites & MF & Ethylene & Acid Sites \\
\hline Toluene & $0.53 \pm 0.04$ & $0.68 \pm 0.02$ & $0.61 \pm 0.04$ & $0.95 \pm 0.04$ & $0.81 \pm 0.05$ & $0.03 \pm 0.06$ \\
ID Isomer \#1 & $0.76 \pm 0.03$ & $0.97 \pm 0.08$ & $0.70 \pm 0.08$ & $1.16 \pm 0.06$ & $0.86 \pm 0.06$ & $-0.40 \pm 0.03$ \\
ID Isomer \#2 & $0.41 \pm 0.05$ & $1.06 \pm 0.11$ & $1.18 \pm 0.01$ & $1.12 \pm 0.04$ & $0.85 \pm 0.07$ & $-0.26 \pm 0.03$ \\
Trimer & $1.34 \pm 0.13$ & $0 \pm 0.14$ & $0.95 \pm 0.20$ & $2.26 \pm 0.30$ & $0 \pm 0.13$ & $0.12 \pm 0.22$ \\
Dimer & $0.64 \pm 0.10$ & $0.41 \pm 0.04$ & $0.96 \pm 0.04$ & $0.09 \pm 0.0$ & $0 \pm 0.02$ & $0.96 \pm 0.04$ \\
\hline
\end{tabular}


Table 3. Simulated Reactions and Kinetic Parameters

\begin{tabular}{|c|c|c|c|c|c|}
\hline No. $^{a}$ & Reaction $^{b}$ & $\mathbf{k}^{\mathbf{c}^{\mathrm{c}}}$ & $\Delta G^{\ddagger} 250^{\circ} C, i^{d}$ & $\mathbf{k}_{-i}{ }^{\mathrm{c}}$ & $\Delta G^{\ddagger}{ }_{250^{\circ}} \mathbf{C , - i}{ }^{d}$ \\
\hline 1 & $M F+E \rightleftharpoons C A$ & $1.1 \times 10^{-4} \mathrm{M}^{-1} \mathrm{~s}^{-1}$ & $40.7(+4.5)$ & $4.9 \times 10^{2} \mathrm{~s}^{-1}$ & $24.8(-6)$ \\
\hline 2 & $C A * \rightarrow \mathrm{T}+W *$ & $3.9 \times 10^{6} \mathrm{~s}^{-1}$ & 15.4 & & \\
\hline 3 & $M F *+W \rightleftharpoons P D I *$ & $2.7 \times 10^{5} \mathrm{M}^{-1} \mathrm{~s}^{-1}$ & 18.2 & $4.5 \times 10^{4} \mathrm{~s}^{-1}$ & 20.1 \\
\hline No. & Adsorption/Desorption & $\overline{K_{\mathbf{i}}}$ & $\Delta G_{\text {ads }, 250^{\circ} C^{d}}$ & & \\
\hline 4 & $C A+* \rightleftharpoons C A *$ & 191 & $-5.5(+7)$ & & \\
\hline 5 & $W+* \rightleftharpoons W *$ & 757 & -6.9 & & \\
\hline 6 & $M F+* \rightleftharpoons M F *$ & 16600 & $-5.5(-5)$ & & \\
\hline 7 & $P D I+* \rightleftharpoons P D I *$ & 338 & -10.1 & & \\
\hline
\end{tabular}

${ }^{\mathrm{a}}$ Elementary steps with a number are used to derive the reduced model.

${ }^{\mathrm{b}}$ Molecules are labeled as follows: $\mathrm{MF}=2$-methylfuran, $\mathrm{E}=$ Ethylene, $\mathrm{CA}=$ Cycloadduct of MF and Ethylene, $\mathrm{T}=$

Toluene, $\mathrm{W}=$ Water, $\mathrm{PDI}=2,5$-Pentanedione, $*=$ Vacant Strong Acid H-BEA Site

"Subscript "i" implies forward reaction while "-i" implies reverse reaction.

${ }^{\mathrm{d}}$ Reaction barriers and adsorption energies are tabulated in units of $\mathrm{kcal} / \mathrm{mol}$. Adjustments to parameters shown in parantheses, consistent with the adjustments made in the prior work ${ }^{37}$ and within expected computational error 


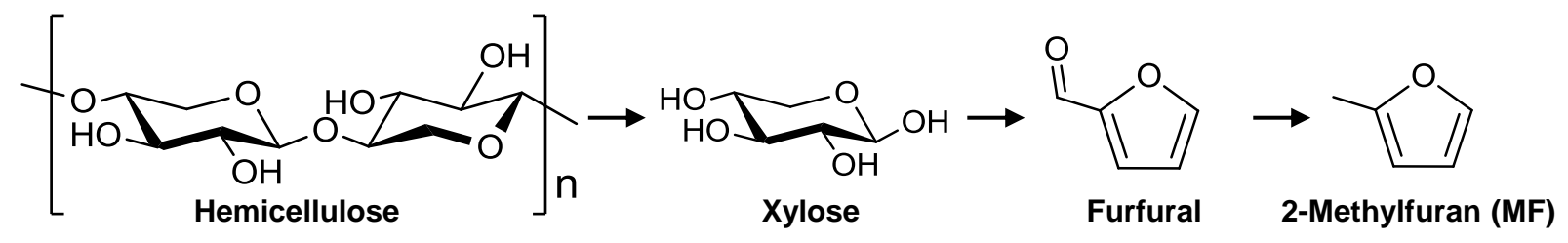

Figure 1. Reactions for Production of 2-Methylfuran from Hemicellulose. 


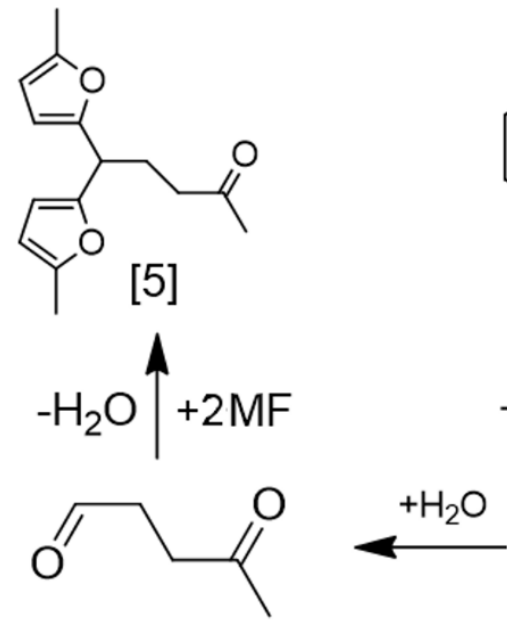

[4]<smiles>Cc1cc2c(C)cccc2o1</smiles>

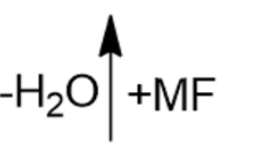<smiles>Cc1ccc(-c2ccc(C)o2)cc1</smiles>

[7]

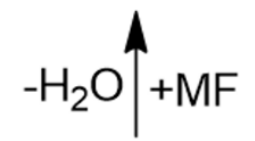<smiles>CCc1ccccc1C</smiles>

[8]

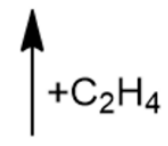

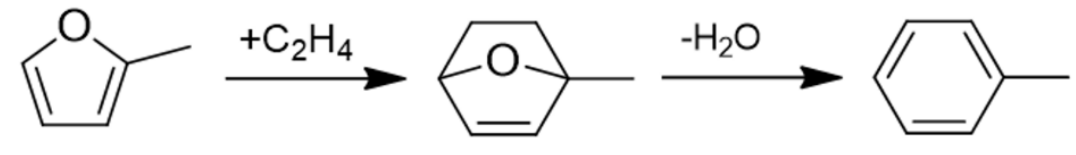

[1]

[2]

Figure 2. Reaction of 2-Methylfuran and Ethylene to Toluene in H-Form Zeolites. Molecules: [1] 2-

Methylfuran (MF), [2] MF/ $\mathrm{C}_{2} \mathrm{H}_{4}$ Cycloadduct, [3] Toluene, [4] 4-Oxopentanal [5] 2-Methyfuran Trimer, [6] 2Methylfuran Dimer, [7] Polymer Product, and [8] Alkylation Product. 

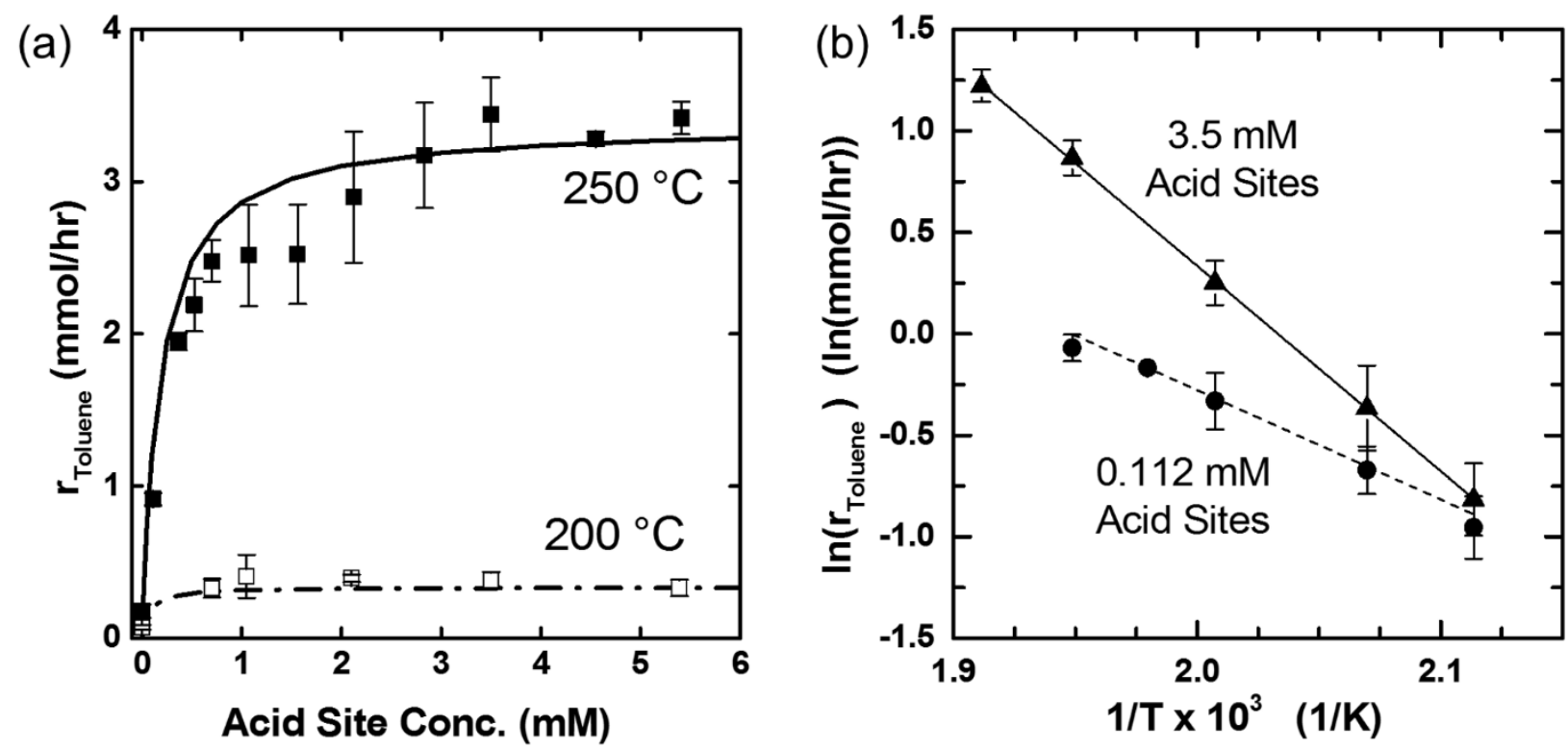

Figure 3. Kinetics of Toluene Production from 2-Methylfuran and Ethylene. (a) Rate of toluene production as a function of Brønsted acid site concentration for the reaction of $\mathrm{MF}$ and ethylene at $200{ }^{\circ} \mathrm{C}$ and $250{ }^{\circ} \mathrm{C}$ with $\mathrm{H}-\mathrm{BEA}$ $(\mathrm{Si} / \mathrm{Al}=12.5)$, where experimental results are shown as boxes and predictions from the reduced model are shown as lines. (b) Arrhenius plots for the production of toluene from MF and ethylene over $0.112 \mathrm{mM} \mathrm{Brønsted} \mathrm{acid} \mathrm{sites} \mathrm{H}$ BEA and $3.5 \mathrm{mM}$ Brønsted acid sites H-BEA. 
(a)

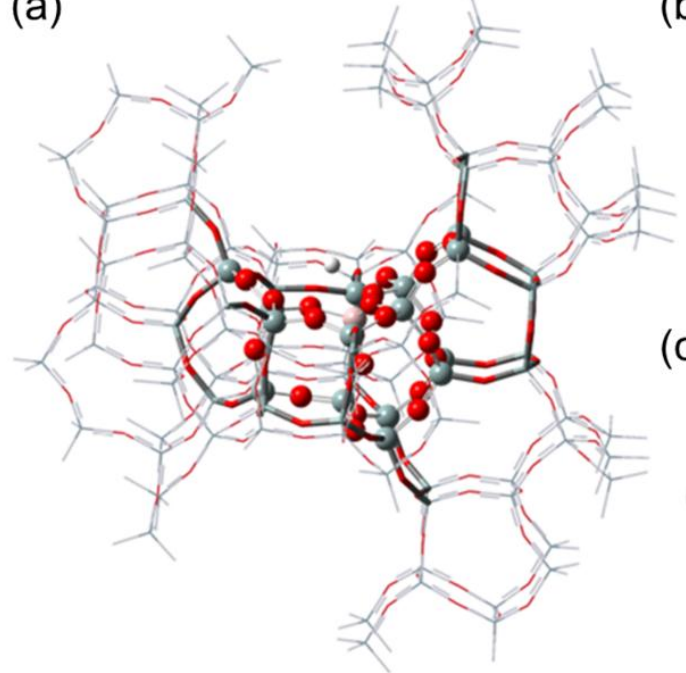

(b)

(c)

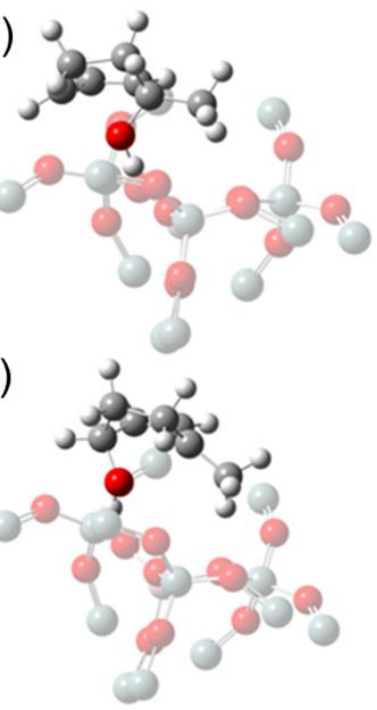

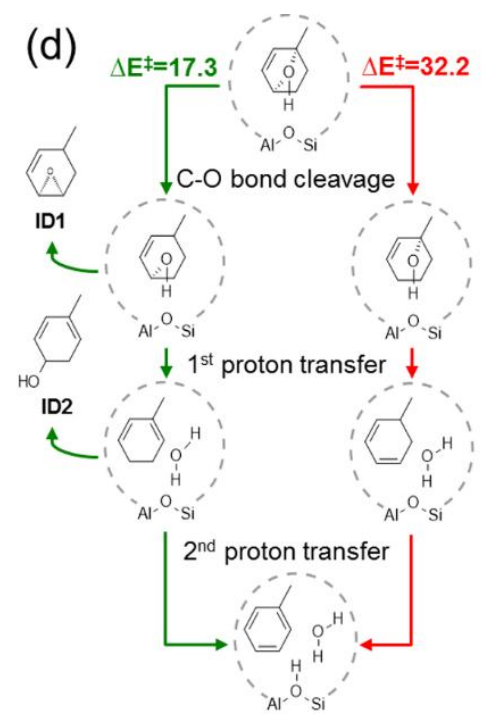

(d)

Figure 4. ONIOM Model of H-BEA Zeolite and Dehydration Reaction with Proposed Reaction Scheme for the Acid-Catalyzed Production of the Incomplete Dehydration Isomers from the MF/Ethylene

Oxanorbornene Intermediate. (a) 3-layer ONIOM model of H-BEA zeolite where ball-and-stick atoms are in the high layer, tubeframe atoms are in the intermediate layer, and wireframe atoms are in the model layer. $\mathrm{C}$-O cleavage steps from the dehydration mechanism within the H-BEA ONIOM model are shown on the (b) non-methyl and (c) methyl sides of the oxanorbornene intermediate. (d) Reaction scheme showing the formation of intermediates from the methyl and non-methyl $\mathrm{C}-\mathrm{O}$ cleavages of the oxanorbornene intermediate. 

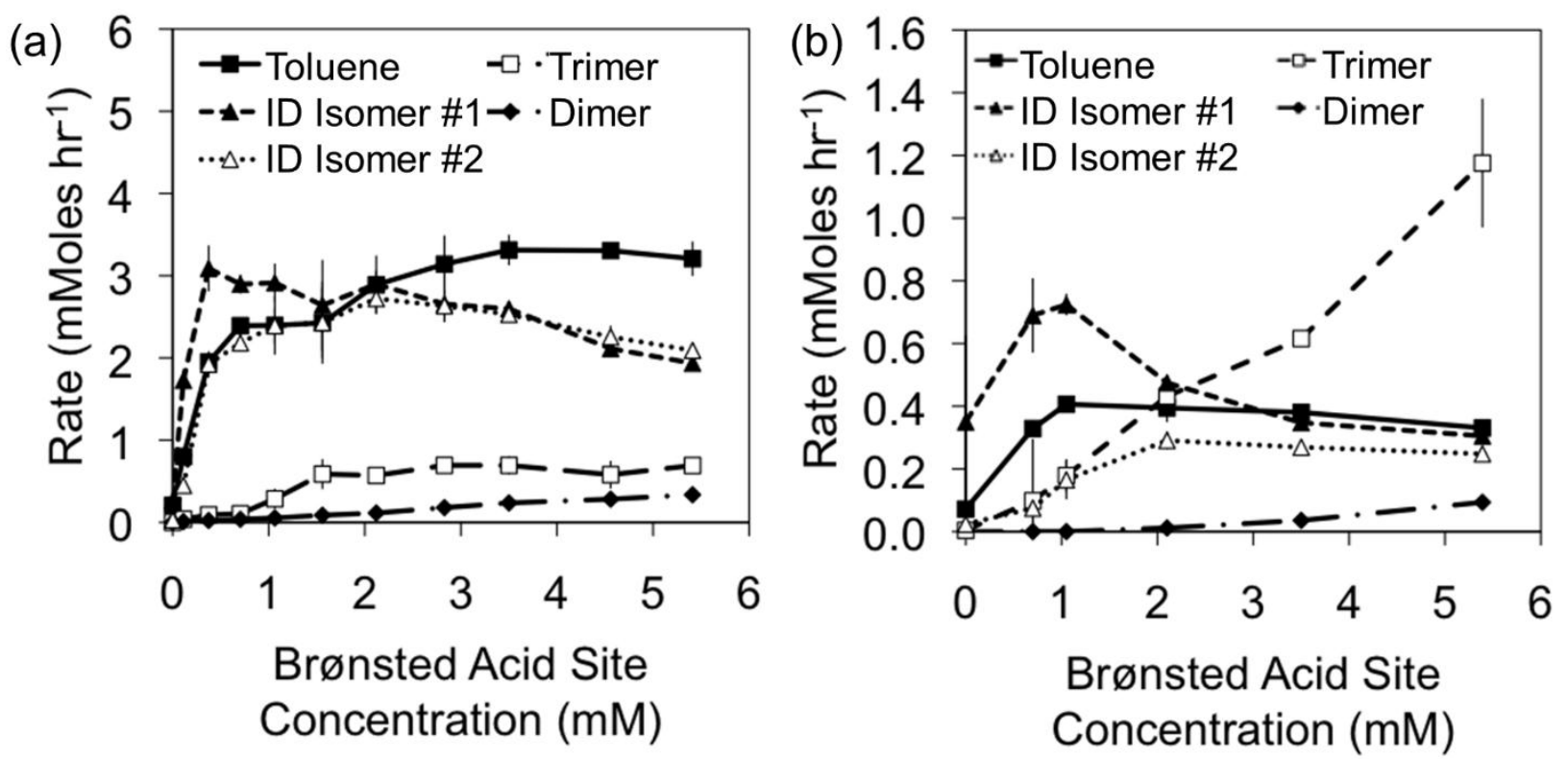

Figure 5. Rate of Side Product Formation from 2-Methylfuran and Ethylene. The rate of production of toluene and the main identified side products as a function of Brønsted acid site concentration for the reaction of MF and ethylene with H-BEA (Si/Al 12.5) catalyst at (a) $250^{\circ} \mathrm{C}$, and (b) $200^{\circ} \mathrm{C}$. 


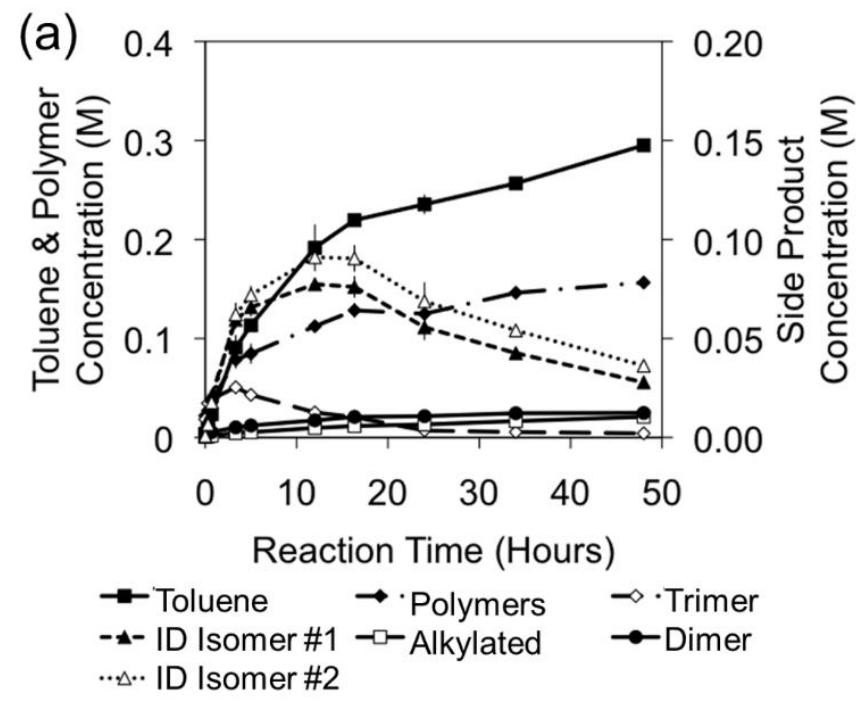

(b)

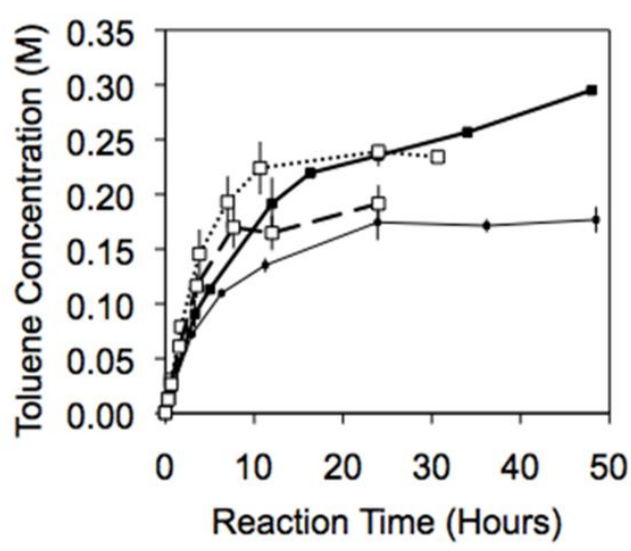

Figure 6. Side Products of 2-Methylfuran and Ethylene with Time. Concentration of (a) toluene and the main side-products and (b) toluene as a function of reaction time for the reaction of MF and ethylene. Experiments conducted data in panel (a) were conducted using 0.3 grams of H-BEA ( $\mathrm{Si} / \mathrm{Al} 12.5$ ) catalyst at $250^{\circ} \mathrm{C}$. 
(a)

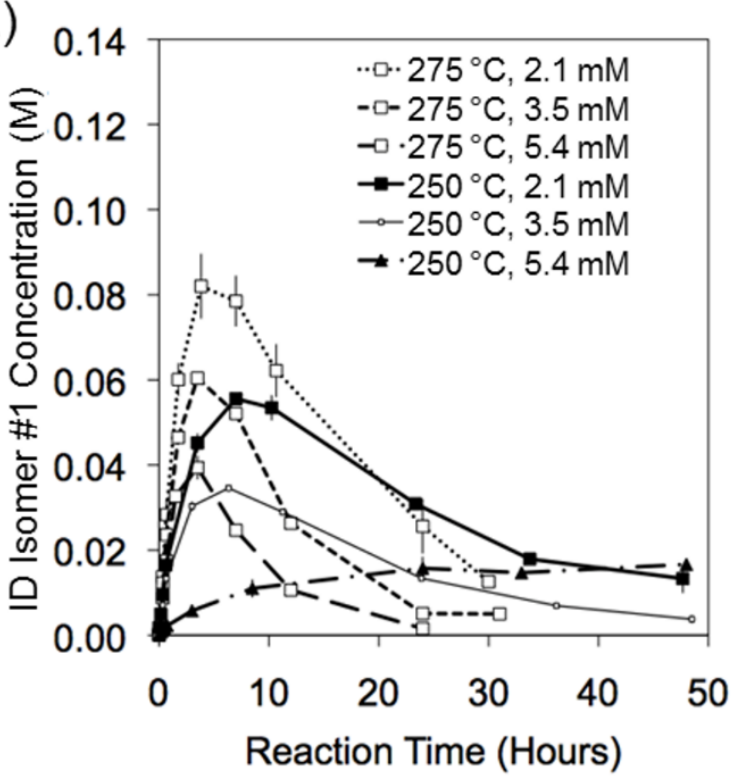

(c)

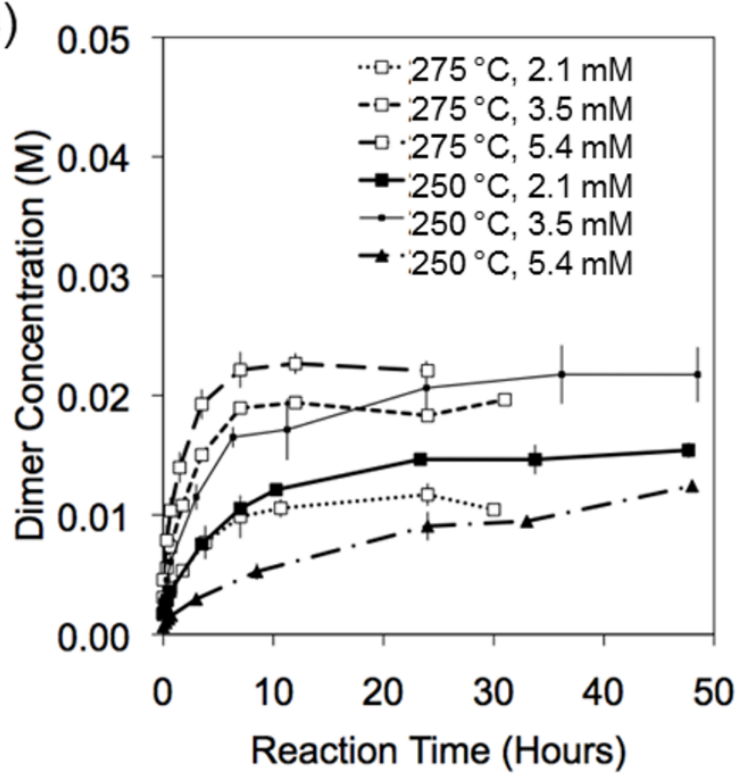

(b)

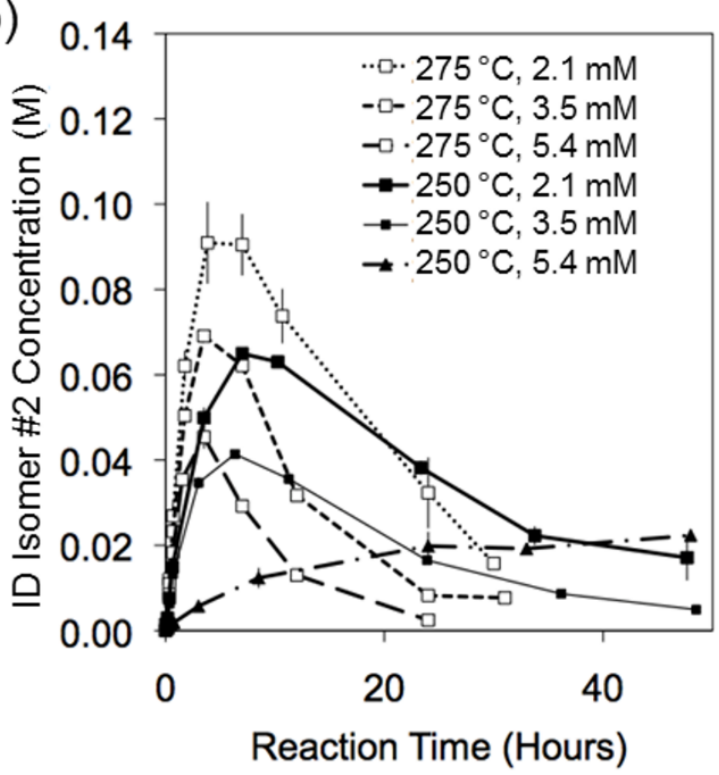

(d)

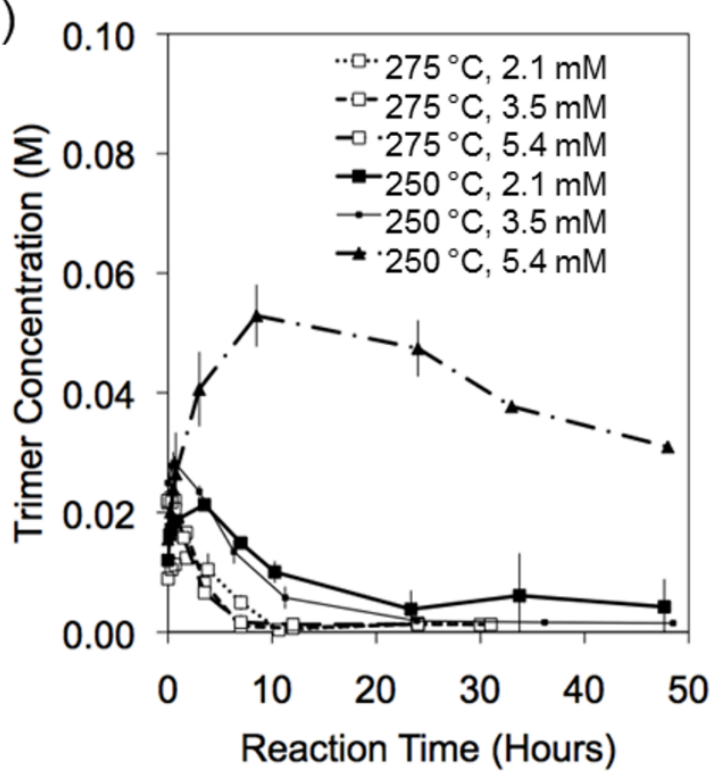

Figure 7. Product Concentrations with Variable Solid Brønsted Acid Catalyst. Product concentrations of (a) ID isomer \#1, (b) ID isomer \#2, (c) MF dimer, and (d) MF trimer as a function of reaction time for the reaction of MF and ethylene over H-BEA at $200-275^{\circ} \mathrm{C}$ over $0.3-0.77$ grams H-BEA. 
(a)

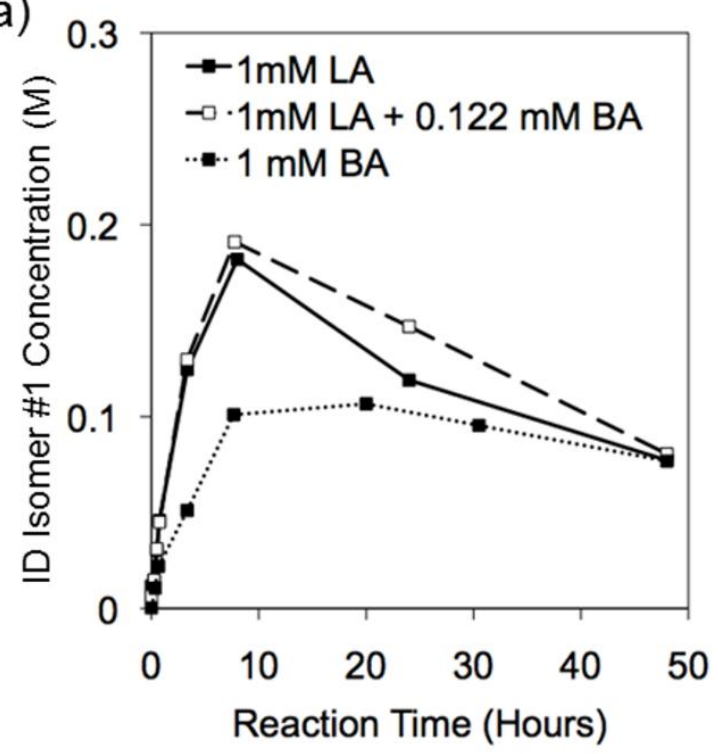

(c)

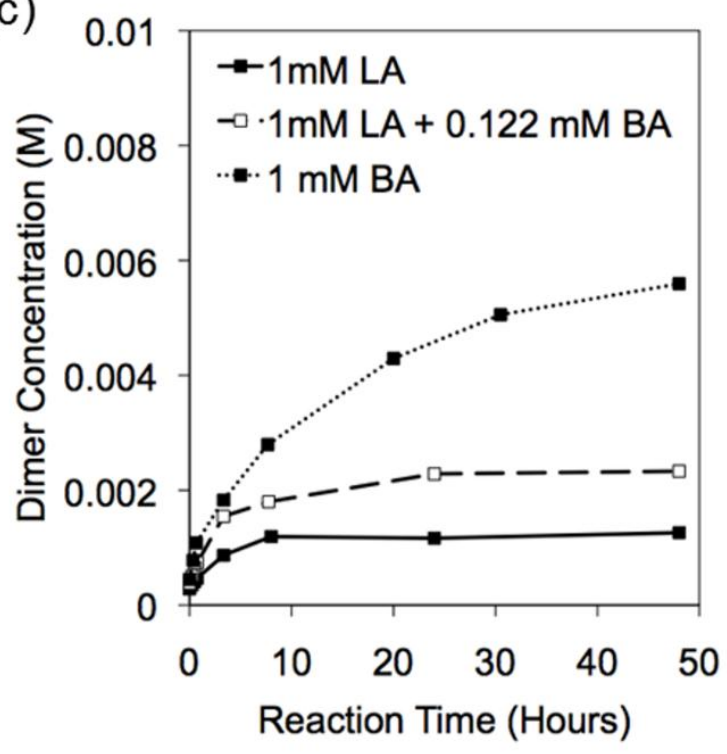

(b)

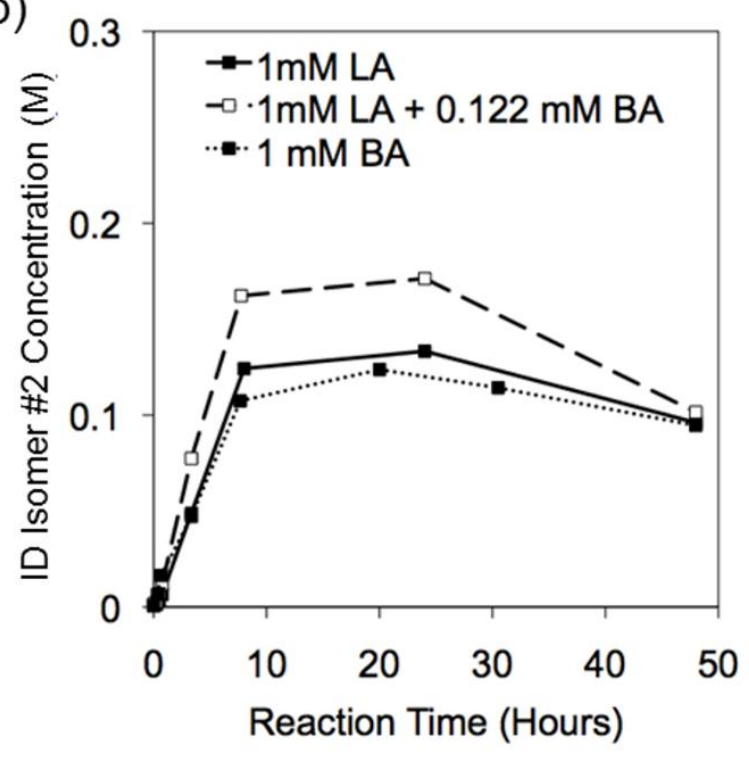

(d)

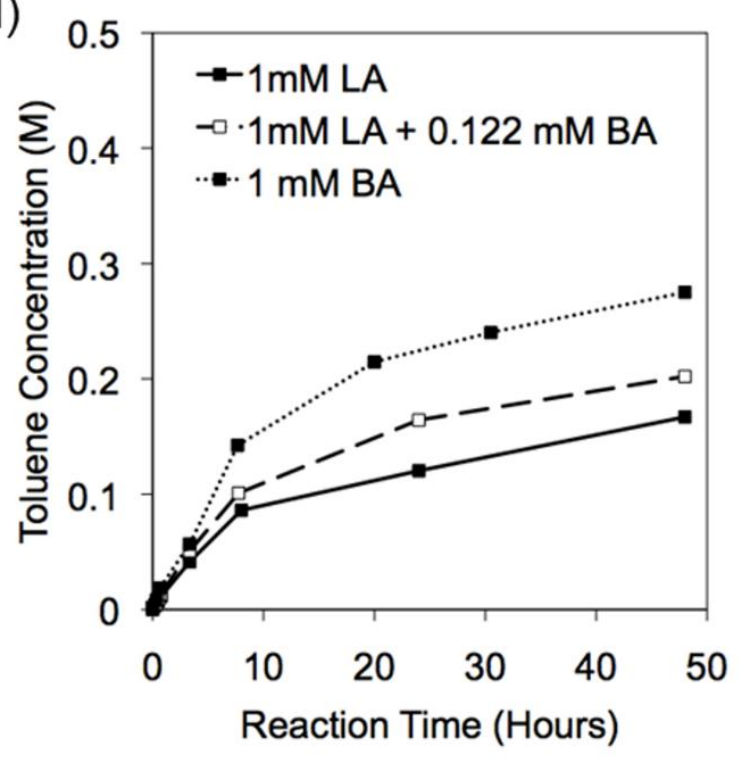

Figure 8. Product Concentrations with Variable Solid Lewis/Brønsted Acid Catalyst. Product concentrations of (a) ID isomer \#1, (b) ID isomer \#2, (c) toluene, and (d) the 2-methylfuran dimer as a function of time for the reaction of 2-methylfuran and ethylene with $1 \mathrm{mM}$ Sn-BEA (Lewis acid - LA), a physical mixture of $1 \mathrm{mM} \mathrm{Sn-}$ BEA and $0.12 \mathrm{mM}$ H-BEA (Si/Al 12.5), and $1 \mathrm{mM} \mathrm{H-BEA} \mathrm{(Brønsted} \mathrm{acid} \mathrm{-} \mathrm{BA)} \mathrm{at} 250{ }^{\circ} \mathrm{C}$. 

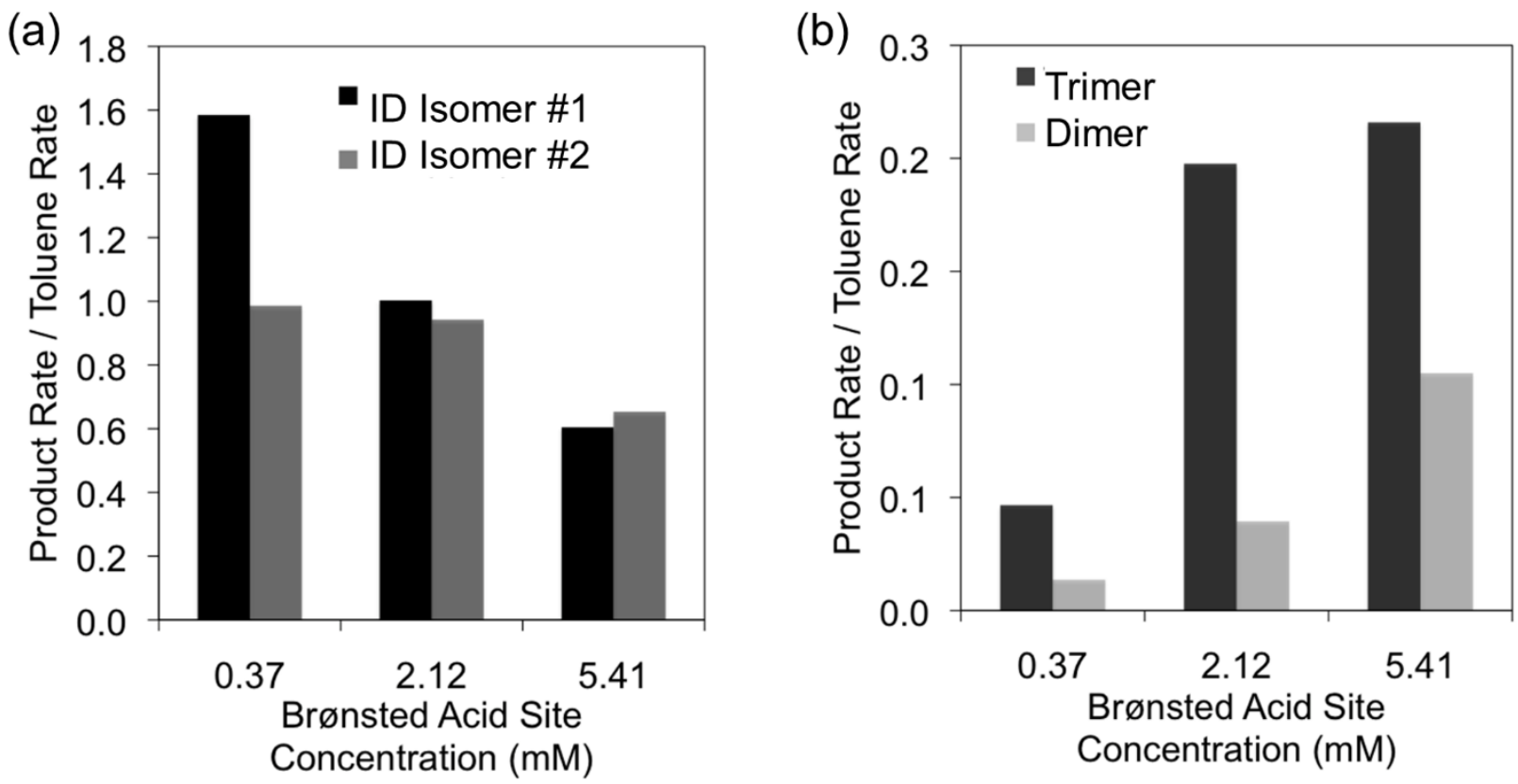

Figure 9. Product Ratios at Varying Acid Concentrations. Ratio of the rate of formation of (a) the ID isomers and (b) the 2-methylfuran trimer and dimer to the rate of formation of toluene from 2-methylfuran and ethylene over H-BEA at $250{ }^{\circ} \mathrm{C}$. 


\section{References}

(1) Christensen, C. H.; Rass-Hansen, J.; Marsden, C. C.; Taarning, E.; Egeblad, K. ChemSusChem 2008, 1, 283-289.

(2) Huber, G. W.; Iborra, S.; Corma, A. Chem. Rev. 2006, 106, 4044-4098.

(3) Climent, M. J.; Corma, A.; Iborra, S. Green Chem. 2011, 13, 520-540.

(4) Carlson, T. R.; Cheng, Y.-T.; Jae, J.; Huber, G. W. Energy Environ. Sci. 2011, 4, 145-161.

(5) Cheng, Y.; Jae, J.; Shi, J.; Fan, W.; Huber, G. W. Angew. Chem. Int. Ed. Engl. 2012, 51, 1387-1390.

(6) Carlson, T. R.; Tompsett, G. a.; Conner, W. C.; Huber, G. W. Top. Catal. 2009, 52, 241-252.

(7) Lligadas, G.; Ronda, J. C.; Galià, M.; Cádiz, V. Polymers (Basel). 2010, 2, 440-453.

(8) Fabri, J.; Graeser, U.; Simo, T. A. Xylenes. Ullmann's Encylopedia Inustrial Chem. 2012, 643-663.

(9) Fruscella, W. Kirk-Othmer Encyclopedia of Chemical Technology Online Edition, Vol. 3, John Wiley \& Sons, Inc.

(10) Partenheimer, W. Catal. Today 1995, 23, 69-158.

(11) Raes, M. C.; Proulx, O. J. US Patent 4506040A 1985.

(12) Raghavendrachar, P.; Ramachandran, S. Ind. Eng. Chem. Res. 1992, 31, 453-462.

(13) Egeblad, K.; Rass-hansen, J.; Marsden, C. C.; Taarning, E.; Christensen, C. H. Catalysis 2009, 13, 13-50.

(14) Vennestrøm, P. N. R.; Osmundsen, C. M.; Christensen, C. H.; Taarning, E. Angew. Chem. Int. Ed. Engl. 2011, 50, 10502-10509.

(15) Cheng, Y.-T.; Huber, G. W. Green Chem. 2012, 14, 3114.

(16) Román-Leshkov, Y.; Barrett, C. J.; Liu, Z. Y.; Dumesic, J. A. Nature 2007, 447, 982-985.

(17) Xiong, K.; Lee, W.-S.; Bhan, A.; Chen, J. G. ChemSusChem 2014, 10027, 1-5.

(18) Jae, J.; Zheng, W.; Lobo, R. F.; Vlachos, D. G. ChemSusChem 2013, 6, 1158-62.

(19) Panagiotopoulou, P.; Vlachos, D. G. Appl. Catal. A Gen. 2014, 480, $17-24$.

(20) Williams, C. L.; Chang, C.; Do, P.; Nikbin, N.; Caratzoulas, S.; Vlachos, D. G.; Lobo, R. F.; Fan, W.; Dauenhauer, P. J. ACS Catal. 2012, 935-939.

(21) Chang, C.-C.; Green, S. K.; Williams, C. L.; Dauenhauer, P. J.; Fan, W. Green Chem. 2014, 6, 585-588.

(22) Mahmoud, E.; Watson, D. A.; Lobo, R. F. Green Chem. 2014, 16, 167- 175. 
(23) Corma, A.; la Torre, O. de; Renz, M.; Villandier, N. Angew. Chem. Int. Ed. Engl. 2011, 50, $2375-2378$.

(24) Li, G.; Li, N.; Wang, Z.; Li, C.; Wang, A.; Wang, X.; Cong, Y.; Zhang, T. ChemSusChem 2012, 5, $1958-66$.

(25) Nikbin, N.; Caratzoulas, S.; Vlachos, D. G. Appl. Catal. A Gen. 2014, 485, 118-122.

(26) Chang, C.-C.; Wang, Z.; Dornath, P.; Je Cho, H.; Fan, W. RSC Adv. 2012, 2, 10475-10477.

(27) Zhao, Y.; Truhlar, D. G. Theor. Chem. Acc. 2007, 120, 215-241.

(28) Baerlocher, C.; McCusker, L. B. Int. Zeolite Assoc. 1996.

(29) Svensson, M.; Froese, R. D. J.; Matsubara, T.; Sieber, S.; Morokuma, K. J. Phys. Chem. 1996, 100, 1935719363.

Rappe, A. K.; Casewit, C. J.; Colwell, K. S.; Goddard III, W. A.; Skiff, W. M. J. Am. Chem. Soc. 1992, 114, 10024-10035.

Frisch, M. J.; Trucks, G. W.; Schlegel, H. B.; Scuseria, G. E.; Robb, M. A.; Cheeseman, J. R.; Scalmani, G.; Barone, V.; Mennucci, B.; Petersson, G. A.; Nakatsuji, H.; Caricato, M.; Li, X.; Hratchian, H. P.; Izmaylov, A. F.; Bloino, J.; Zheng, G.; Sonnenberg, J. L.; Hada, M.; Ehara, M.; Toyota, K.; Fukuda, R.; Hasegawa, J.; Ishida, M.; Nakajima, T.; Honda, Y.; Kitao, O.; Nakai, H.; Vreven, T.; Montgomery, J. A.; Jr., J. E. P.; Ogliaro, F.; Bearpark, M.; Heyd, J. J.; Brothers, E.; Kudin, K. N. .; Staroverov, V. N.; Kobayashi, R.; Normand, J.; Raghavachari, K.; Rendell, A.; Burant, J. C.; Iyengar, S. S.; Tomasi, J.; Cossi, M.; Rega, N.; Millam, J. M.; Klene, M.; Knox, J. E.; Cross, J. B.; Bakken, V.; Adamo, C. ; Jaramillo, J.; Gomperts, R.; Stratmann, R. E.; Yazyev, O.; Austin, A. J.; Cammi, R.; Pomelli, C.; Ochterski, J. W.; Martin, R. L.; Morokuma, K.; Zakrzewski, V. G.; Voth, G. A.; Salvador, P.; Dannenberg, J. J.; Dapprich, S.; Daniels, A. D.; Farkas, Ö.; Foresman, J. B.; Ortiz, J. V.; Cioslowski, J.; Fox, D. J. Gaussian 092009.

(32) Nikbin, N.; Do, P. T.; Caratzoulas, S.; Lobo, R. F.; Dauenhauer, P. J.; Vlachos, D. G. J. Catal. 2013, 297, 35-43.

(33) Corma, A.; la Torre, O. de; Renz, M. ChemSusChem 2011, 4, 1574-1577.

(34) Corma, A.; la Torre, O. de; Renz, M. Energy Environ. Sci. 2012, 5, 6328-6344.

(35) Li, G.; Li, N.; Yang, J.; Wang, A.; Wang, X.; Cong, Y.; Zhang, T. Bioresour. Technol. 2013, 134, 66-72.

(36) Sims, J.; Duke, R. E.; Strozier, R. W.; Birge, R. R.; Sustmann, R.; Fueno, T.; Yamaguchi, K. J. Am. Chem. Soc. 1973, 95, 4094-4096. 
(37) Patet, R. E.; Nikbin, N.; Williams, C. L.; Green, S. K.; Chang, C.-C.; Fan, W.; Caratzoulas, S.; Dauenhauer, P. J.; Vlachos, D. G. ACS Catal. 2015, 5, 2367-2375.

(38) Patet, R.; Nikbin, N.; Williams, C. L.; Green, S. K.; Chang, C. C.; Fan, W.; Caratzoulas, S.; Dauenhauer, P.; Vlachos, D. G. ACS Catal. 2014, Submitted.

(39) Pacheco, J. J.; Davis, M. E. 2014, 1-5.

(40) Loudon, G. M. Organic Chemistry; 4th ed.; Oxford University Press: New York, 2002; p. 410.

(41) Nikbin, N.; Caratzoulas, S.; Vlachos, D. G. ChemSusChem 2013, 6, 2066-2068.

(42) Rai, N.; Caratzoulas, S.; Vlachos, D. G. ACS Catal. 2013, 3, 2294-2298. 
Graphical Abstract

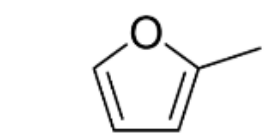

2-Methylfuran

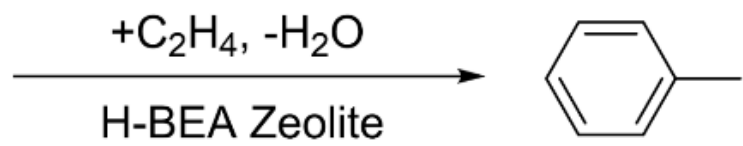

200- $275^{\circ} \mathrm{C}$ 200 psi ethylene
Toluene $46 \%$ Selectivity 